International Journal of Engineering, Science and Technology

Vol. 3, No. 1, 2011, pp. 166-182
INTERNATIONAL

JOURNAL OF

ENGINEERING,

SCIENCE AND

TECHNOLOGY

www.ijest-ng.com

(C) 2011 MultiCraft Limited. All rights reserved

\title{
Dynamic response of fly ash reinforced functionally graded rubber composite sandwiches - a Taguchi approach
}

\author{
M. R. Doddamani*, S. M. Kulkarni \\ Department of Mechanical Engineering, National Institute of Technology Karnataka, Surathkal - 575025, INDIA \\ "Corresponding Author: e-mail: mrd_phd@rediffmail.com, Tel +91-9448920878, Fax.+91-824-2474033
}

\begin{abstract}
The dynamic analysis of jute-epoxy sandwiches with fly ash reinforced functionally gradient (FG) flexible, compliant rubber core is presented. FG samples are prepared using conventional casting technique. Presence of gradation is quantified by weight method. An attempt is made to study the influence of fly ash weight fraction, jute orientation and core to total thickness $(\mathrm{C} / \mathrm{H})$ of sandwich on damping ratio (DR) and natural frequency (NF). The design of experiments based upon L9 $\left(3^{3}\right)$ orthogonal arrays by Taguchi is used. Analysis of variance (ANOVA) and S/N (signal to noise) ratios analysis is performed on measured data to investigate the influence of material and geometrical parameters on dynamic response. An optimal parameter combination is determined which leads to higher DR and NF. A correlation derived from the results of Taguchi experimental design is proposed as a predictive equation for estimation of these properties of sandwiches. These correlations are obtained by multiple regressions. It is demonstrated that the predicted results obtained using these equations are consistent with experimental observations.
\end{abstract}

Keywords: Functionally graded sandwich, damping ratio, natural frequency, Taguchi etc.

\section{Introduction}

Because of its outstanding bending rigidity, low specific weight, superior isolating qualities, excellent vibration characteristics and good fatigue properties, sandwich construction is utilized for almost five decades (Le-Chung Shiau et al, 2006). These are composed of two stiff, strong and thin faces (skins) bonded to a light, thick weaker core. Faces sustain in-plane and bending loads, while the core resist transverse shear forces and keep the facings in place (Vinson, 1999). Nowadays, the use of sandwich construction is further enhanced by the introduction of laminated composites as faces of the sandwich panels (Hwu et al, 2004). Sandwiches provide increased flexural rigidity and strength by virtue of their geometry (Ostergaard, 2006; Berthelot, 1999; Ferreira et al, 1998). As the factors coming under the broad spectrum of microscopical, compositional arrangement and/or chemical structure are known to influence the mechanical (modulus, strength etc.) properties (Zenkert, 1997; Marc André Meyers et al, 2008; Dias et al, 2010; Cannillo et al, 2007) they need to be considered in any new developmental effort involving sandwich structures. Sandwich composites is having widespread application in engineering as load carrying structural members with high strength to weight ratios (Banerjee, 2003). As sandwich construction are having many advantages over conventional materials it is used in aeronautical applications for more than 50 years (Zenkert, 1995; Allen, 1969; Plantema, 1966).

The dynamic behaviour of sandwich beams is well researched and the literature is around for nearly half a century (Birman, 2002; Sisemore et al, 2002; Sokolinsky et al., 2002; Choi, 2003; Nabarrete et al., 2003; Bozhevolnaya et al., 2004; Kapuria et al., 2004; Meyer-Piening, 2004; Plagianakos et al., 2004; Ruzzene, 2004; Sokolinsky et al., 2004; Ganesan et al., 2005; Hao et al., 2005; Numayr et al., 2005; Yang et al., 2005; Yang et al., 2005). One of the most prominent properties investigated by number of researchers is the vibration analysis. A comprehensive study of large amplitude free vibrations of plates using approximate analytical and numerical methods (finite element) is presented in the available literature (Sathyamoorthy, 1983; Ambartsumyan, 1970; Hassert et al.,1962; Wu et al., 1969; Wu et al., 1971; Berger, 1955; Whitney et al., 1969; Chandra, 1976; Chandra et al., 1975; Reddy et al., 1981). Finite element analysis is used to solve large amplitude free vibration analysis (Reddy et al., 1981 and 1982) of anisotropic composite plates by using the first-order shear deformation theory. Another important factor that largely 
affects the results of the sandwich beam analysis is the assumed vibration behaviour of the layers. The simplest sandwich beam model utilizes Euler-Bernoulli theory for the face layers and only allows the core to deform only in shear (Banerjee, 2003; Ahmed, 1971 and 1972; Mead et al., 1968; Fasana et al., 2001; Baber et al., 1998; Hashemi et al., 2009). The published literature on the free vibration analysis of sandwich beams deals mainly with three-layered sandwich beams that are elastic (and sometimes viscoelastic), homogeneous and isotropic, but rigidly joined together, and for which the top and bottom layers are generally made of strong materials such as steel or aluminium whereas the core (i.e. the middle layer) is relatively soft for example rubber or honeycomb structures so as to provide adequate damping and good energy absorption characteristics. Sandwich systems are not been fully exploited in structural applications due to damage tolerance concerns (Avery et al, 2000). Although sandwich structures offer advantages over other types of structures, it is important to develop new types of materials in order to obtain the absolute minimum weight for given conditions such as structural geometry and loadings. These new sandwiches should be compared with other sandwich construction as well as with alternative structures in order to select the best configuration. One of the new alternatives is a sandwich structure with functionally graded (FG) cores.

A sandwich which exhibits lesser deflection for larger load applied could be realized by using a FG core. Functionally graded materials (FGMs') are those in which properties change from point to point within them. FGMs' are gained large applicability as thermal-barriers (Chakraborty et al, 2003). In recent years FGMs' are gained considerable importance as materials to be used in extremely high temperature environments such as nuclear reactors and high-speed spacecraft industries (Yamanouchi, 1990). FGMs are first introduced by a group of scientists in Sendai Japan in 1984 (Koizumi, 1997). These are new inhomogeneous materials, in which the mechanical properties vary smoothly and continuously from one surface to the other. This is achieved by gradually varying the volume fraction of the constituent materials. This continuous change in composition results in the graded properties of FGMs' (Reddy et al, 2001). This gradation in properties of the material reduces thermal stresses, residual stresses and stress concentration factors (Reddy et al, 1999). Nature provides many examples of functionally graded materials. They can be found in bones, plant stems, bamboo (Amada et al, 2001; Amada et al., 1997) and soils. Manufacturing methods include: highspeed centrifugal casting method (Fukui et al., 1997; Fukui, 1991), ultraviolet radiations (Lambros et al., 1999), electrophoretic deposition (Sarkar et al., 1997), dispersing microballoons (with linear graded volume fraction) in epoxy (El-Hadek et al, 2003), high temperature infiltration (Suresh, 2001), chemical vapor deposition, powder metallurgy, plasma sprays and self-propagating combustion synthesis (Koizumi, 1997). Although fabrication technology of FGMs' is in its infancy they are having a great potential in many applications ranging from dental implants (Watari et al., 1997) to thermal coatings and thermal protection systems (Koizumi, 1997).

As the use of FGMs' increases new methodologies are to be developed to characterize them, and to design and analyze structural components made with these materials. The methods should be such that they can be incorporated into available methods with minimal modifications, if any. One problem is that of response of structures made of polymeric FGMs' to free vibration. As many of the polymeric systems for developing FGM's are generally with the tag of expensiveness associated, it is decided to examine the gradation in composition and its subsequent behavior under vibration when an abundantly available lower density possessing fly ashes are the filler materials for the core. Fly ashes are fine particulate waste products derived during generation of power in a thermal power plant. These are having aspect ratios closer to unity and hence are expected to display near isotropic characteristics. These inexpensive and possessing good mechanical properties, when used with well established matrix systems help to reduce the cost of the system and at the same time either retain or improve specific and desirable mechanical properties. Fly ash is attracted interest (Ferrigno, 1978; Mohapatra et al., 2001) lately, because of the abundance in terms of the volume of the material generated and the environmental-linked problems in the subsequent disposal. Fly ash mainly consists of alumina and silica, which are expected to improve the composite properties. Fly ash also consists to some extent, hollow spherical particles (termed cenospheres (Pedlow et al., 1978; Kulkarni et al., 2002)) which aid in maintenance of lower density values for the composite, a feature of considerable significance in weight-specific applications. Again, as the fillers do not come under irregular shape, the resin spread, is better and as the ashes are essentially a mixture of solid, hollow and composite particles displaying near isotropic properties, developing newer and utilitarian systems using them should be an interesting and challenging task (Kulkarni et al., 2002). Further in this effort for the skins too, it is decided to employ instead of the well explored man-made fibers like glass, carbon or aramid a fairly strong but naturally occurring one going by the name 'jute fiber' and known for its inexpensiveness. There is a renewed interest in using sandwich construction with fiber composites such as jute/glass-epoxy as skins owing to their high stiffness and compatibility with different core materials. Jute reinforced plastics offer attractive propositions for cost-effective applications (Mohan et al., 1983). These in the form of laminates are having much better properties than their neat resin counterparts (Shah et al., 1981). Better properties of woven jute fabric reinforced composites demonstrated their potential for use in a number of consumable goods in an earlier literature (Gowda et al., 1999). Substantial increases in flexural modulus and strength with small amounts of reinforcement of unidirectional jute are also been reported (Mohan et al., 1985). For fabricating both the skins and core a matrix system is required. A thermosetting epoxy is chosen for this purpose as far as the skins are concerned. As the important thing is to produce gradation in the composition of the core, the lightness and a slightly varying density owing to the existence of different morphologies for the ash, namely, whether it is plerosphere or cenospheres or a composite type is fully made use of to yield a composite with a matrix material consisting of rubber. Here again, more from the standpoint of cost, availability and the scarce literature (Chakraborty et al., 2003; Apetre et al., 2003; Sankar, 2001) prompted for going in for an elastomeric material which is naturally occurring and known by the name 'natural rubber' for the matrix material.

The concept of FG material as core made of rubber (natural latex) and its influence on mechanical performance of sandwiches is scarcely available in early literature (Evans et al, 2001; Wadley et al, 2003). This makes increasing thrust in continuing research in 
this area as evident from the literature. In particular, free vibration analysis of sandwich composites is carried out by a number of investigators (Mead et al, 1966; Ahmed et al, 1971; Rao et al, 1978; Rahmani et al, 2010; Arvin et al, 2010; Arikoglu et al, 2010). But these studies restrict themselves by focusing on use of homogeneous core. In recent past few studies are talked about behavior of sandwiches for FG cores (Li et al, 2008; Rahmani et al, 2009; Chehel Amirani et al, 2009; Noureddine El Meiche et al, 2011; Kashtalyan et al, 2009; Hosseini-Hashemi et al, 2011) focusing on numerical studies. To the best of the authors' knowledge there is no published work on free vibration analysis of fly ash reinforced FG sandwich composite through an experimental route. As it can be seen, investigation on the dynamic characterization of such composites is scarce at best. As the applications of such composite beams become more advanced, one would need to gain a better understanding of their dynamic behavior in particular damping ratio and natural frequency and to contribute in building a wider database for understanding their basic dynamic properties. This is therefore the underlying motivation for our investigation.

As an attempt to fill this gap, the present work is undertaken with an objective to explore the potential of fly ash as a filler material in FG rubber composite sandwiches for the dynamic performance. Though sandwich with FG cores are studied by many researchers earlier, very few of them deal in experimental investigation of damping behavior. An economic and viable experimental strategy based on Taguchi's parameter design is used to analyze effect of various parameters considered in this study (Siddhartha et al, 2011; Mahapatra et al, 2009; Moshat et al, 2010; Mathivanan et al, 2010; Datta et al, 2010; Elangovan et al, 2010; Venkateswarlu et al, 2010).

The aim of the present study is to investigate damping ratio (DR) as mentioned in ASTM E 756-05(2010) and subsequently natural frequency (NF). Average values of five replicates are statistically analyzed. An attempt in the present investigation is to find the influence of three main factors namely weight fraction of fly ash, orientation of jute fabric and $\mathrm{C} / \mathrm{H}$ ratio on $\mathrm{DR}$ and $\mathrm{NF}$ and to establish correlation between them.

\section{Taguchi Technique}

Taguchi's techniques are being used widely in engineering design (Ross, 1996) (Phadke, 1989). Taguchi technique is a powerful tool for the design of high quality systems (Taguchi et al, 1987; Taguchi, 1993; Ross, 1988; Montgomery 2001). The main trust of Taguchi's techniques is the use of parameter design, which is an engineering method for product or process design that focuses on determining the parameter (factor) settings producing the best levels of a quality characteristic (performance measure) with minimum variation. This method is effective to deal with responses influenced by multi-variables. It drastically reduces the number of experiments that are required to model the response function compared with full factorial design of experiments. It is a technique for designing and performing experiments to investigate processes where the output depends on many factors (variables, inputs) without having tediously and uneconomically run of the process using all possible combinations of values. Taguchi designs provide a powerful and efficient method for designing processes that operate consistently and optimally over a variety of conditions. To determine the best design, it requires the use of a strategically designed experiment, which exposes the process to various levels of design parameters. The major advantage of this technique is to find out the possible interaction between the parameters. The Taguchi technique is devised for process optimization and identification of optimal combination of the factors for a given response (Basavarajappa et al, 2005).

Experimental design methods are developed in the early years of 20th century and are being extensively studied by statisticians since then, but they are not easy to use by practitioners (Phadke, 1989). Taguchi's approach to design of experiments is easy to be adopted and applied for users with limited knowledge of statistics; hence it is gained a wide popularity in the engineering and scientific community. This technique is divided into three main phases, which encompasses all experimentation approaches. The three phases are (1) the planning phase (2) the conducting phase and (3) the analysis phase. Planning phase is the most important phase of the experiment. This technique creates a standard orthogonal array (OA) to accommodate the effect of several factors on the target value and defines the plan of experiments. The experimental results are analyzed using analysis of means and variance to study the influence of factors. Figure 1 presents the scheme of the major steps of implementing the Taguchi method (Montgomery, 2001).

This method employs a generic signal-to-noise $(\mathrm{S} / \mathrm{N})$ ratio to quantify the variation. These $\mathrm{S} / \mathrm{N}$ ratios are meant to be used as measures of the effect of noise factors on performance characteristics. $\mathrm{S} / \mathrm{N}$ ratios take into account both, amount of variability in the response data and closeness of the average response to target. The $\mathrm{S} / \mathrm{N}$ ratio characteristics can be divided into three categories given by Eqs. (1) to (3), when the characteristic is continuous:

Nominal is the best characteristic,

$$
\frac{S}{N}=10 \log \frac{\bar{y}}{S_{y}^{2}}
$$

Smaller is the best characteristic,

$$
\frac{S}{N}=-10 \log \frac{1}{n}\left(\sum y^{2}\right)
$$

Larger the better characteristic,

$$
\frac{S}{N}=-10 \log \frac{1}{n}\left(\sum \frac{1}{y^{2}}\right)
$$


where $\bar{y}$ is the average of observed data, $S_{y}^{2}$ the variation of $y, n$ the number of observations and $y$ the observed data. With the above $\mathrm{S} / \mathrm{N}$ ratio transformation, larger the $\mathrm{S} / \mathrm{N}$ ratio, the better is the result for $\mathrm{DR}$ and $\mathrm{NF}$. Analysis of variance (ANOVA) is a mathematical technique, which is based on a least square approach. The treatment of the experimental results is based on the analysis of average and ANOVA.

\section{Materials and Method}

\subsection{Materials}

The matrix system consists of Natural latex supplied by Karnataka Forest Development Corporation Ltd., Rubber division, Sullia, Karnataka, India. The density of latex is found to be $1060 \mathrm{~kg} / \mathrm{m}^{3}$. The filler used i.e. fly ash, is obtained from Raichur Thermal Power Plant, Raichur (India). This ASTM class ' $\mathrm{C}$ ' fly ash with bulk density of about $900 \mathrm{~kg} / \mathrm{m}^{3}$ and a true particle density of about $2550 \mathrm{Kg} / \mathrm{m}^{3}$ is found to consist of a mixture of solid and hollow spheres of assorted sizes. Energy dispersive spectroscopy of the fly ash sample revealed the main constituents to be silica and alumina of about $63 \%$ and $26 \%$ respectively

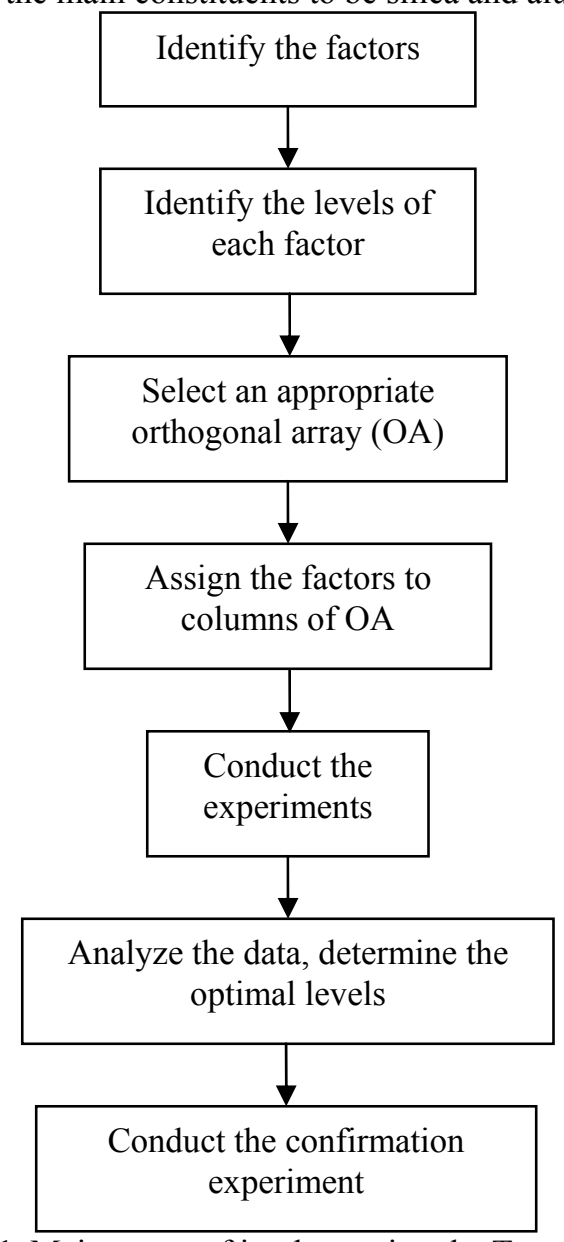

Figure 1. Major steps of implementing the Taguchi method

(Kishore et al, 2002). Particle size distribution of fly ash is determined by the Malvern ${ }^{\circledR}$ make laser light particle size analyzer. Tough the mean particle size, given by the numerical data by the analyzer, is about $18 \mu \mathrm{m}$ (specific surface area of $2.6439 \mathrm{~m}^{2} / \mathrm{g}$ ) two distinct clusters emphasizing a gross bimodal nature in the particle distribution is observed. One of the clusters is having a distribution of mean size of $35 \mu \mathrm{m}$ while the other about $0.35 \mu \mathrm{m}$. Whereas $73 \%$ of the particles come from a larger average-sized particles, the remaining $27 \%$ contain the smaller $(0.35 \mu \mathrm{m})$ average size.

\subsection{Processing}

For processing of FG cores, conventional casting technique is utilized. Fly ash, the filler used for core consists of, as emphasized before, a mixture of solid (gray ash particles $-2.5 \mathrm{~g} / \mathrm{cm}^{3}$ ), hollow (cenosphere -0.5 to $0.6 \mathrm{~g} / \mathrm{cm}^{3}$ ) and composite particles (plerosphere -0.8 to $2.0 \mathrm{~g} / \mathrm{cm}^{3}$ ) possessing different densities having resemblance to spherical form to a larger degree. Presence of gradation in prepared specimens is expected due to these variable density particles present in fly ash which settle while solidifying at different depths. A measured quantity of natural latex and sulphur ( $1 \mathrm{pphr}-1$ part by mass per 100 parts by mass of rubber) is mixed with a pre-weighed amount of fly ash with gentle stirring for about 1 hour. The mould for specimen preparation 
( $200 \mathrm{~mm} \mathrm{X} 45 \mathrm{~mm}$ X $10 \mathrm{~mm}$ ) is completely covered on all sides with teflon sheet. Subsequently silicone releasing agent is applied for easy removal of the cast sample. The mixture is then slowly decanted into the mould. The mixture is left to cure at $90^{\circ} \mathrm{C}$ in an oven for about 5-6 hours. The cured rigid plate sample is withdrawn from the mould and the edges are trimmed to size $180 \mathrm{~mm} \mathrm{X}$ $35 \mathrm{~mm} \mathrm{X}$ thickness $(4,6$ and $8 \mathrm{~mm})$. The core samples thus made are tested to physically quantify presence of ash gradation through the thickness and subsequently used for sandwich construction. Bi-directional woven jute is used for sandwich face configuration. The skins are cut into layers of dimensions $180 \mathrm{~mm} \mathrm{X} 35 \mathrm{~mm}$ in required orientation. Then all layers of jute skin are heated in the oven at $70^{\circ} \mathrm{C}$ for 5-10 minutes to remove moisture present. These heated skins are dipped in mixture of epoxy and $\mathrm{K}$ 6 hardener. The required number of jute layers is stacked on base plate forming the bottom face of sandwich. Subsequently epoxy dipped FG core is placed. Few more skins are stacked on top of the core. Finally, the top plate is tightened to squeeze out excessive resin resulting in proper wetting of entire structure. The mould assembly is then cured at room temperature for about 2426 hrs. Prepared sandwich slabs are illustrated in Figure 2 showing top view (Figure 2 (a)) with different orientations and front view (Figure 2 (b)) with varying $\mathrm{C} / \mathrm{H}$ ratio. Figure 3 depicts typical FGM sandwich with $0^{\circ} / 90^{\circ}$ orientation.

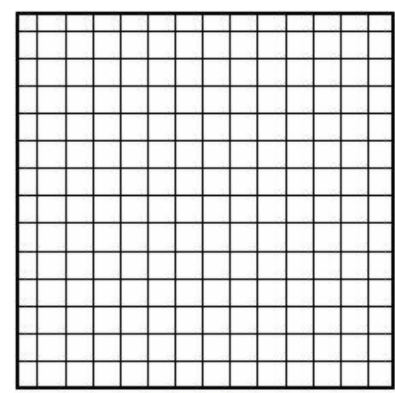

$0^{\circ} / 90^{\circ}$

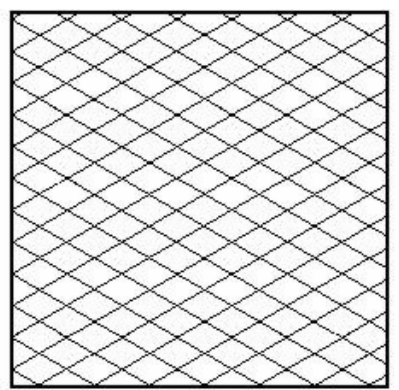

$30^{\circ} \% 0^{\circ}$

Figure 2. (a) Orientation of jute skins

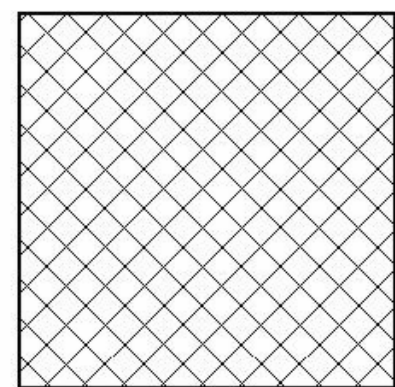

$45^{0} / 45^{0}$
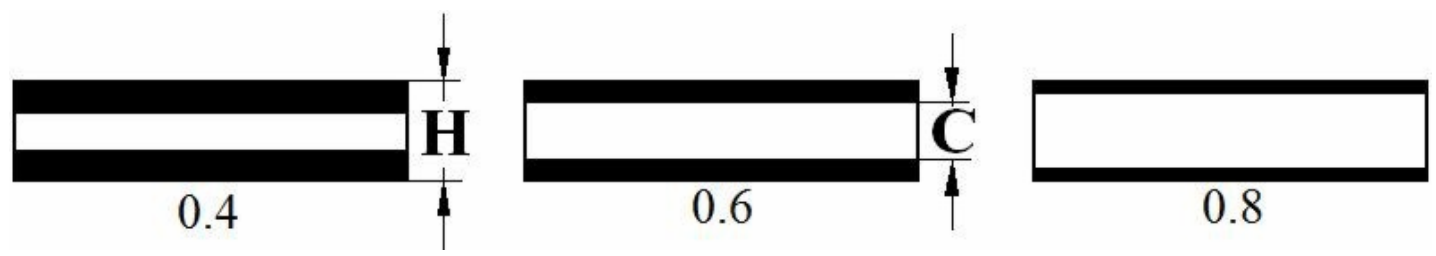

Figure 2. (b) Core thickness $(\mathrm{C})$ to total thickness $(\mathrm{H})$ of sandwich $(\mathrm{C} / \mathrm{H}$ ratio)

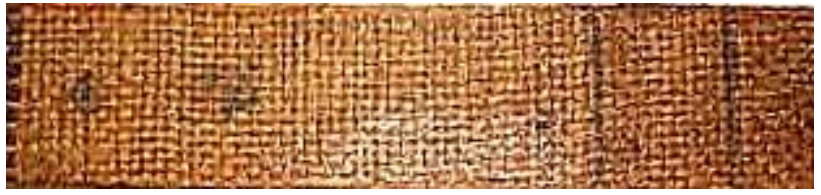

Figure 3. Jute skin orientation in sandwich for $0^{\circ} / 90^{\circ}$ configuration

\subsection{Tests for physical properties}

\subsubsection{Gradation Test for FG core}

Fly ash consists of a mixture of solid, hollow and composite particles possessing to a larger degree resemblance to spherical appearance. Hollow fly ash particles are termed as Cenospheres while composite particles which consist of smaller solid particles in hollow spherical particles, are referred as Plerospheres. Presence of gradation in prepared specimens is attributed towards these variable density particles present in fly ash which settle while solidifying at different depths. Figure 4 presents schematics of functional gradation in prepared core samples. To physically quantify the gradation using weight method, a separate test slab of 10 $\mathrm{mm} \times 10 \mathrm{~mm} \times 10 \mathrm{~mm}$ is cut from the sample. FG core samples are cut into four slices of dimension $10 \mathrm{~mm}$ X $10 \mathrm{~mm} \times 2.5 \mathrm{~mm}$. 


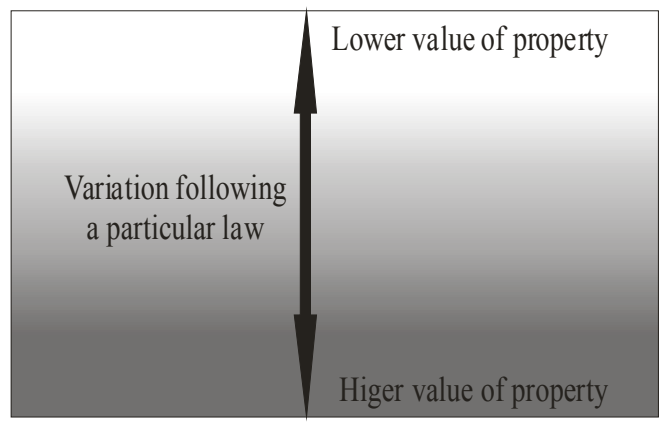

Figure 4. Schematics of gradation in prepared FG samples

Each slice cut from different portion of the slab of pure rubber is weighed. Similarly slices of same dimension are cut from the FG rubber sample and weighed. The weight $\%$ of fly ash in each layer is computed by, $\%$ weight of fly ash $=\{[$ FG core slice weight $(\mathrm{g})$ - slice weight of pure rubber $(\mathrm{g})] /$ Weight of FG core slice $(\mathrm{g})\}$

$$
\mathrm{x} 100
$$

\subsubsection{Density characterization for Sandwiches}

ASTM C 271-05 standard is followed for density estimation of sandwich samples.

\subsection{Experimental setup and procedure}

Several methods of analysis for estimating the damping ratio are cited in recent past (Naghipour et al, 2005) outlining details of five techniques used for determining the damping of beams based on both time as well as frequency domain methods. The methods elaborated in the time domain are the logarithmic decrement analysis (LDA) and the Hilbert transform analysis (HTA) methods. In the frequency method, the moving block analysis (MBA), half- power bandwidth (HPB) and modification of HPB method referred to M-HPBT. These methods can be used for estimation of damping ratio, even for materials with high level of damping (more than 5\%) or low level (less than 2\%). Most prominent among these is LDA being more accurate. For the present study LDA is used for determining the damping ratio in the time domain analysis of a vibrating system. The logarithm of the ratio of the amplitudes of two oscillations that are $\mathrm{n}$ cycles apart from each other, on the decaying transient of a single degree of freedom system, is designated as the logarithmic decrement.

In the present study, damping measurement (E756-05(2010)) is carried out for sandwich of FG core having the configuration as shown in figure 4. Figure 5 shows experimental setup for the test. Mounting arrangement is depicted by Figure 6 . To measure the vibration signals AD3101 M12 with sensitivity $9.8 \mathrm{mv} / \mathrm{g}$ piezoelectric accelerometer is used. In order to acquire these signals NI PXI-1050 chassis containing NI PXI 4472 DAQ with 24bit ADC having 8 analog input channels is used.

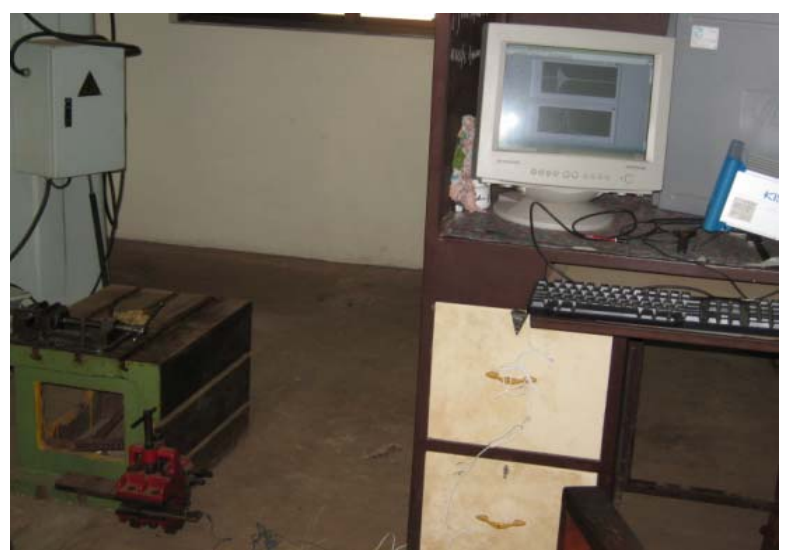

Figure 5. Experimental setup 


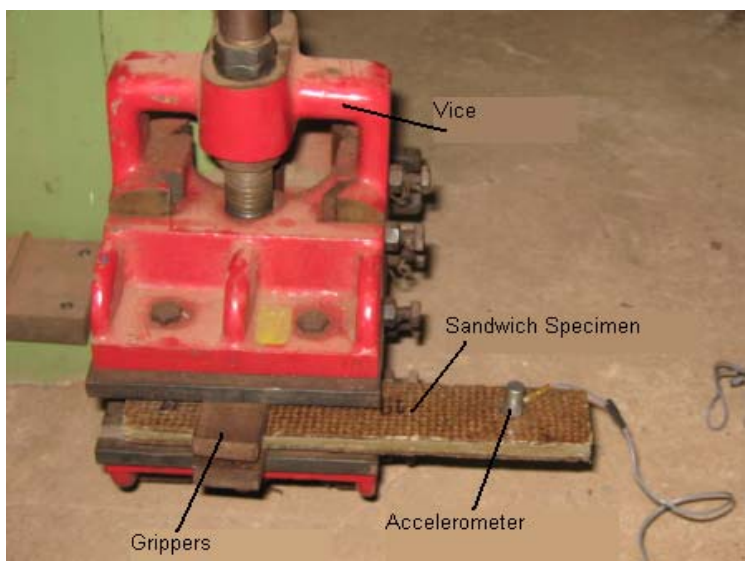

Figure 6. Specimen mounting

Figure 7 presents typical output of damping test as seen on computer screen. Damping ratio is obtained from the displacementtime plot for free vibration of specimen. Figure 8 shows the typical plot of displacement vs. time for FGM sample.

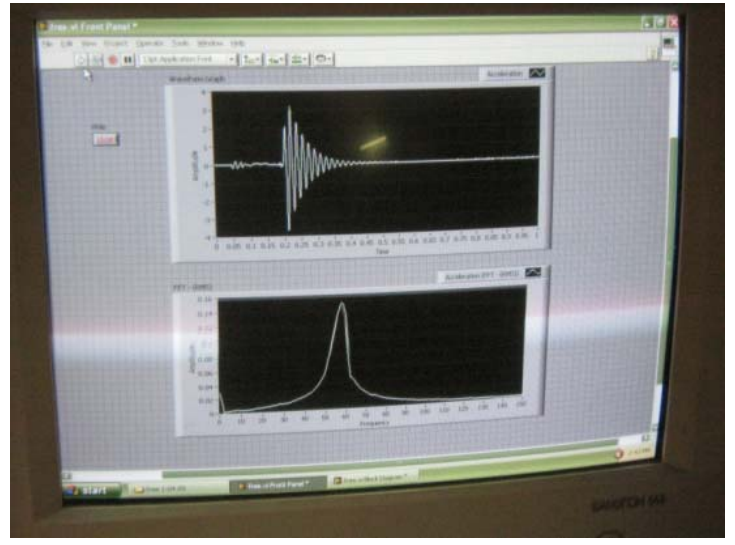

Figure 7. Output on screen

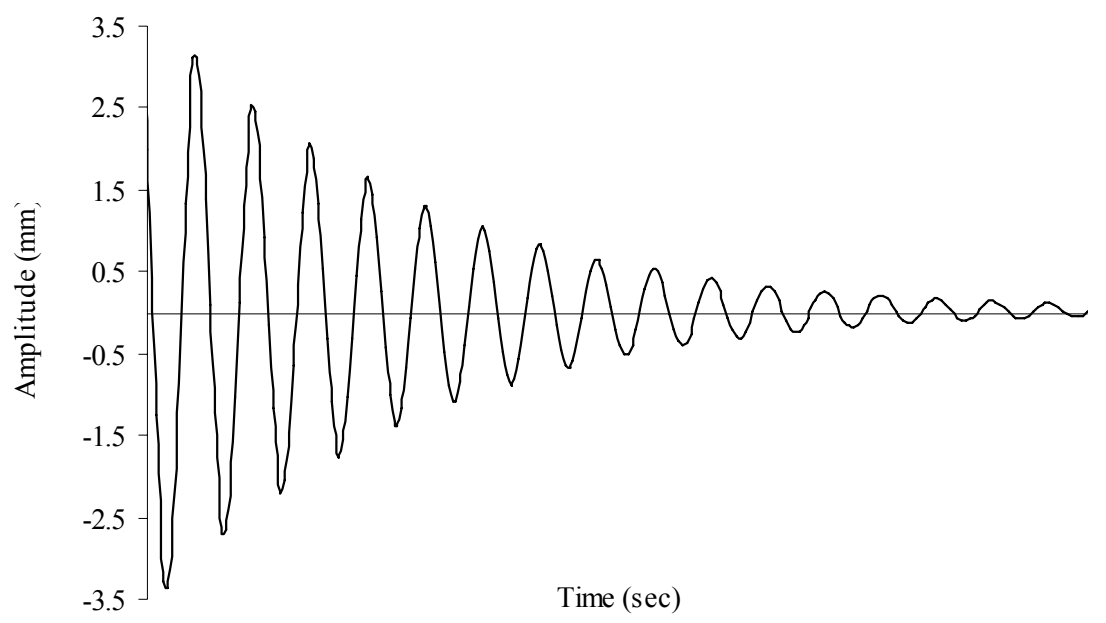

Figure 8. Typical displacement vs. time curve

The logarithmic decrement, $\delta$ is represented by, (Naghipour et al, 2005)

$$
\delta=\operatorname{In} \frac{Y_{m}}{Y_{m+n}} \quad \text { where } Y_{m} \text { and } Y_{m+n} \text { are amplitudes }
$$

Damping ratio $\xi$, for the case where the time $t$ is increased by the damped period can be expressed by,

$$
\delta=\frac{2 \pi \xi}{\sqrt{1-\xi^{2}}}
$$




\subsection{Plan of the experiment}

The experiments are conducted as per the standard OA (Taguchi et al, 1987; Taguchi, 1993; Ross, 1988; Montgomery 2001). In the present investigation an L9 orthogonal array is chosen, which is having 9 rows and 3 columns as shown in Table 1.

Table 1. Orthogonal array L9 $\left(3^{3}\right)$ of Taguchi

\begin{tabular}{cccc}
\hline L9 $\left(3^{3}\right)$ Test & 1 & 2 & 3 \\
\hline 1 & 1 & 1 & 1 \\
2 & 1 & 2 & 2 \\
3 & 1 & 3 & 3 \\
4 & 2 & 1 & 2 \\
5 & 2 & 2 & 3 \\
6 & 2 & 3 & 1 \\
7 & 3 & 1 & 3 \\
8 & 3 & 2 & 1 \\
9 & 3 & 3 & 2 \\
\hline
\end{tabular}

Sandwich systems are having two major components as emphasized before namely skins and core. Skins are generally of cross woven fabric type whose strength (load carrying capacity) comes from its orientation. With increase in orientation angle load bearing capacity decreases. For $0^{0} / 90^{\circ}$ orientation it is maximum while minimum for $45^{\circ} / 45^{\circ}$. Core is the weaker part which can be reinforced to enhance properties of the sandwiches as a whole. In damping studies as in the current case one major aspect need to be focused is energy absorption which in turn depends upon $\mathrm{C} / \mathrm{H}$ ratio. For the present study, material parameter chosen for the experiments is fly ash weight fraction $(10 \%, 20 \%, 30 \%)$ while geometrical parameters are orientation of jute fabric $\left(0^{\circ} / 90^{\circ}, 30^{\circ} / 60^{\circ}\right.$, $\left.45^{\circ} / 45^{\circ}\right)$ and $\mathrm{C} / \mathrm{H}$ ratio $(0.4,0.6,0.8)$. Table 2 indicates the factors and their level. Difficulties are observed in concern with processing (stirring the mixture of filler and ash) of FG cores for more than $30 \%$ of ash addition. For selecting levels for jute orientation a thought is given with reference to earlier published work which discusses decrease in load bearing capacity with increase in orientation angle. Levels for $\mathrm{C} / \mathrm{H}$ ratios are chosen to present influence of skins as well as core thickness in a profound manner, if any. In the available literature it is shown that the thickness of the damping layer (in our case core) is having a strong influence on the system's response (Mead et al., 1968).

Table 2. Parameters with their values at three levels

\begin{tabular}{cccc}
\hline Level & Fly ash weight fraction, W $(\%)$ & Orientation of Jute Fabric, $\mathrm{O}\left({ }^{\circ}\right)$ & $\mathrm{C} / \mathrm{H}$ Ratio, $\mathrm{R}$ \\
\hline 1 & 10 & $0^{0} / 90^{0}$ & 0.4 \\
2 & 20 & $30^{0} / 60^{0}$ & 0.6 \\
3 & 30 & $45^{0} / 45^{0}$ & 0.8 \\
\hline
\end{tabular}

The experiment consists of 9 (equivalent to 27 experiments in result effectiveness - Taguchi et al, 1987; Taguchi, 1993; Ross, 1988; Montgomery 2001) tests indicating each row in the L9 OA and the parameters representing columns. The first column in Table 2 is assigned to weight fraction of fly ash (W); second column to orientation of jute skin $(\mathrm{O})$ and third column is assigned to $\mathrm{C} / \mathrm{H}$ ratio (R). The experiments are conducted as per the OA with level of parameters given in each array row. After assigning appropriate level settings, the $\mathrm{S} / \mathrm{N}$ analysis is employed to evaluate experimental results with the objective as larger, as the better (Eq. 3) for DR and NF. Five replicates are tested resulting in 45 tests in all to allow ANOVA of the results. It is performed to identify the process parameters that are statistically significant. With the S/N and ANOVA analyses, the optimal combinations of the parameters are proposed. Finally, a confirmation experiment is conducted to verify the predicted values from the regression model with their experimental counterparts.

\section{Results and discussions}

\subsection{Physical properties}

\subsubsection{Gradation characterization for FG core}

Weight method on FG core is conducted for gradation characterization. Table 3 presents the results obtained from equation 4. We can observe clearly from Table 3 that with increase in layer number, fly ash weight fraction (\%) gradually increases. Fly ash weight $\%$ increases with gradual transition from upper to lower layer confirming presence of gradation. 
Table 3. Results (average) obtained in weight method for FG core

\begin{tabular}{cccccc}
$\begin{array}{c}\text { Fly ash } \\
\%\end{array}$ & $\begin{array}{c}\text { Layer } \\
\text { No. }\end{array}$ & $\begin{array}{c}\text { Avg. Wt. Of } \\
\text { Sample With fly } \\
\text { Ash (g) }\end{array}$ & $\begin{array}{c}\text { Avg. Wt. Of } \\
\text { Pure sample } \\
(\mathrm{g})\end{array}$ & $\begin{array}{c}\text { Actual Wt. \% Of fly } \\
\text { Ash / layer }\end{array}$ & $\begin{array}{c}\text { Theoretical Wt. \% Of } \\
\text { fly Ash / layer }\end{array}$ \\
\hline \multirow{3}{*}{10} & 1 & 0.25618 & 0.25375 & 0.9493 & 1 \\
& 2 & 0.25881 & 0.25375 & 1.9574 & 2 \\
& 3 & 0.26151 & 0.25375 & 2.9689 & 3 \\
\hline \multirow{3}{*}{20} & 4 & 0.26425 & 0.25375 & 3.975 & 2 \\
& 1 & 0.25881 & 0.25375 & 1.9559 & 6 \\
& 2 & 0.26424 & 0.25375 & 3.9699 & 6 \\
\hline \multirow{3}{*}{30} & 3 & 0.26984 & 0.25375 & 5.9642 & 6 \\
& 4 & 0.27575 & 0.25375 & 7.9796 & 9 \\
\hline
\end{tabular}

Note: Layer 1 - top layer, Layer 2 - bottom layer

\subsubsection{Sandwich density}

Density is a fundamental physical property that can be used in conjunction with other properties to characterize the sandwiches. Most sandwich structural properties, such as strength and stiffness, are proportional to the density. The density test method provides a standard method of obtaining sandwich density data for design properties, material specifications, research and development applications and quality assurance. Sandwich densities calculated (ASTM C 271-05) are presented in Table 4.

Table 4. Densities of sandwich samples

\begin{tabular}{cccccccccc}
\hline & \multirow{2}{*}{ Test } & $\mathrm{W}$ & $\mathrm{O}$ & & \multicolumn{6}{c}{ Specimen Replicates } & \begin{tabular}{c} 
Avg. \\
\cline { 5 - 9 }
\end{tabular} \\
\cline { 5 - 9 } & $(\%)$ & $\left.{ }^{\circ}\right)$ & $\mathrm{R}$ & 1 & 2 & 3 & 4 & 5 & $\begin{array}{c}\text { Density } \\
\left(\mathrm{g} / \mathrm{cm}^{3}\right)\end{array}$ \\
\hline 1 & 10 & $0^{0} / 90^{0}$ & 0.4 & 0.99989 & 0.99699 & 0.99898 & 0.99896 & 0.99899 & 0.99876 \\
2 & 10 & $30^{0} / 60^{0}$ & 0.6 & 0.91996 & 0.92987 & 0.92666 & 0.92736 & 0.92946 & 0.92666 \\
3 & 10 & $45^{0} / 45^{0}$ & 0.8 & 0.89651 & 0.89198 & 0.89751 & 0.88979 & 0.90676 & 0.89651 \\
\hline 4 & 20 & $0^{0} / 90^{0}$ & 0.6 & 1.0699 & 1.069 & 1.0745 & 1.0797 & 1.0794 & 1.0745 \\
5 & 20 & $30^{0} / 60^{0}$ & 0.8 & 1.02762 & 1.02845 & 1.02762 & 1.02762 & 1.0268 & 1.02762 \\
6 & 20 & $45^{0} / 45^{0}$ & 0.4 & 0.94499 & 0.95099 & 0.94897 & 0.94892 & 0.94896 & 0.94857 \\
\hline 7 & 30 & $0^{0} / 90^{0}$ & 0.8 & 1.12111 & 1.12111 & 1.12111 & 1.10111 & 1.14111 & 1.12111 \\
8 & 30 & $30^{0} / 60^{0}$ & 0.4 & 1.03333 & 1.02995 & 1.03333 & 1.04003 & 1.03003 & 1.03333 \\
9 & 30 & $45^{0} / 45^{0}$ & 0.6 & 0.98196 & 0.97498 & 0.97198 & 0.97298 & 0.97098 & 0.97458 \\
\hline
\end{tabular}

\subsection{Statistical analysis}

The plan of tests are developed with the aim of relating the weight fraction of fly ash (W), orientation of jute skin $(\mathrm{O})$ and $\mathrm{C} / \mathrm{H}$ ratio (R) with DR and NF of the sandwiches. On conducting the experiments as per OA, results for various combinations of parameters are obtained (Table 5 and Table 6).

Table 5. Experimental design using L9 OA for damping ratio

\begin{tabular}{|c|c|c|c|c|c|c|c|c|c|c|}
\hline \multirow{2}{*}{ Test } & \multirow{2}{*}{$\begin{array}{l}\mathrm{W} \\
(\%)\end{array}$} & \multirow{2}{*}{$\begin{array}{l}\mathrm{O} \\
\left(^{\circ}\right)\end{array}$} & \multirow{2}{*}{$\mathrm{R}$} & \multicolumn{5}{|c|}{ Specimen Replicates } & \multirow{2}{*}{ Avg. DR } & \multirow{2}{*}{$\begin{array}{c}\text { S/N ratio } \\
\text { (dB) }\end{array}$} \\
\hline & & & & 1 & 2 & 3 & 4 & 5 & & \\
\hline 1 & 10 & $0^{0} / 90^{\circ}$ & 0.4 & 0.0304 & 0.0302 & 0.0302 & 0.0302 & 0.03 & 0.0302 & -30.40 \\
\hline 2 & 10 & $30^{\circ} / 60^{0}$ & 0.6 & 0.03595 & 0.03593 & 0.03594 & 0.03593 & 0.0359 & 0.03593 & -28.89 \\
\hline 3 & 10 & $45^{0} / 45^{0}$ & 0.8 & 0.03963 & 0.0396 & 0.03963 & 0.04 & 0.03963 & 0.03963 & -28.04 \\
\hline 4 & 20 & $0^{0} / 90^{0}$ & 0.6 & 0.03925 & 0.03926 & 0.03926 & 0.03926 & 0.0393 & 0.03926 & -28.12 \\
\hline 5 & 20 & $30^{\circ} / 60^{\circ}$ & 0.8 & 0.04918 & 0.0492 & 0.04918 & 0.04918 & 0.0492 & 0.04918 & -26.16 \\
\hline 6 & 20 & $45^{0} / 45^{0}$ & 0.4 & 0.03759 & 0.03761 & 0.03761 & 0.03761 & 0.0376 & 0.03761 & -28.49 \\
\hline 7 & 30 & $0^{0} / 90^{0}$ & 0.8 & 0.0553 & 0.0553 & 0.0553 & 0.06 & 0.0554 & 0.0553 & -25.15 \\
\hline 8 & 30 & $30^{\circ} / 60^{0}$ & 0.4 & 0.04632 & 0.0463 & 0.04632 & 0.04632 & 0.0464 & 0.04632 & -26.68 \\
\hline 9 & 30 & $45^{0} / 45^{0}$ & 0.6 & 0.05026 & 0.05027 & 0.05027 & 0.05 & 0.0503 & 0.05027 & -25.97 \\
\hline
\end{tabular}


Table 6. Experimental design using L9 OA for natural frequency

\begin{tabular}{|c|c|c|c|c|c|c|c|c|c|c|}
\hline \multirow[b]{2}{*}{ Test } & \multirow{2}{*}{$\begin{array}{l}\mathrm{W} \\
(\%)\end{array}$} & \multirow{2}{*}{$\begin{array}{l}\mathrm{O} \\
\left(^{\circ}\right)\end{array}$} & \multirow[b]{2}{*}{$\mathrm{R}$} & \multicolumn{5}{|c|}{ Specimen Replicates } & \multirow{2}{*}{$\begin{array}{c}\text { Avg. } \\
\text { NF }\end{array}$} & \multirow{2}{*}{$\begin{array}{l}\mathrm{S} / \mathrm{N} \\
\text { ratio } \\
(\mathrm{dB})\end{array}$} \\
\hline & & & & 1 & 2 & 3 & 4 & 5 & & \\
\hline 1 & 10 & $0^{0} / 90^{0}$ & 0.4 & 98.67 & 98.67 & 98.67 & 98.66 & 98.68 & 98.67 & 39.88 \\
\hline 2 & 10 & $30^{\circ} / 60^{0}$ & 0.6 & 78.29 & 78.35 & 78.33 & 78.33 & 78.33 & 78.33 & 37.88 \\
\hline 3 & 10 & $45^{0} / 45^{0}$ & 0.8 & 57.66 & 57.67 & 57.67 & 57.67 & 57.68 & 57.67 & 35.22 \\
\hline 4 & 20 & $0^{0} / 90^{\circ}$ & 0.6 & 68.03 & 68.00 & 67.99 & 68.00 & 68.00 & 68.00 & 36.65 \\
\hline 5 & 20 & $30^{\circ} / 60^{0}$ & 0.8 & 50.67 & 50.67 & 50.67 & 50.67 & 50.67 & 50.67 & 34.09 \\
\hline 6 & 20 & $45^{0} / 45^{0}$ & 0.4 & 73.00 & 73.00 & 72.98 & 73.01 & 73.00 & 73.00 & 37.27 \\
\hline 7 & 30 & $0^{0} / 90^{0}$ & 0.8 & 46.97 & 47.02 & 47.00 & 47.00 & 47.00 & 47.00 & 33.44 \\
\hline 8 & 30 & $30^{\circ} / 60^{0}$ & 0.4 & 72.88 & 72.88 & 72.88 & 72.88 & 72.88 & 72.88 & 37.25 \\
\hline 9 & 30 & $45^{0} / 45^{0}$ & 0.6 & 60.79 & 60.79 & 60.79 & 60.79 & 60.79 & 60.79 & 35.68 \\
\hline
\end{tabular}

In Table 5 and Table 6, the $\mathrm{S} / \mathrm{N}$ ratio for DR and NF is shown for different combination of factor setting as per experimental design. The $\mathrm{S} / \mathrm{N}$ ratio for $\mathrm{DR}$ and $\mathrm{NF}$ is calculated for five repeats under each combination of factor settings. The overall mean for the $\mathrm{S} / \mathrm{N}$ ratio of the $\mathrm{DR}$ and $\mathrm{NF}$ happens to be $-27.55 \mathrm{~dB}$ and $36.38 \mathrm{~dB}$ respectively.

\subsubsection{Main effects plot for $S / N$ ratios}

Figure 9 and 10 present graphically the effect of the three control factors on DR and NF respectively. Analysis of the result leads to the conclusion that factor combination of W3, O2 and R3 gives maximum DR (Figure 9) and for NF factor combination of W1, $\mathrm{O} 1$ and R1 yields higher values (Figure 10).

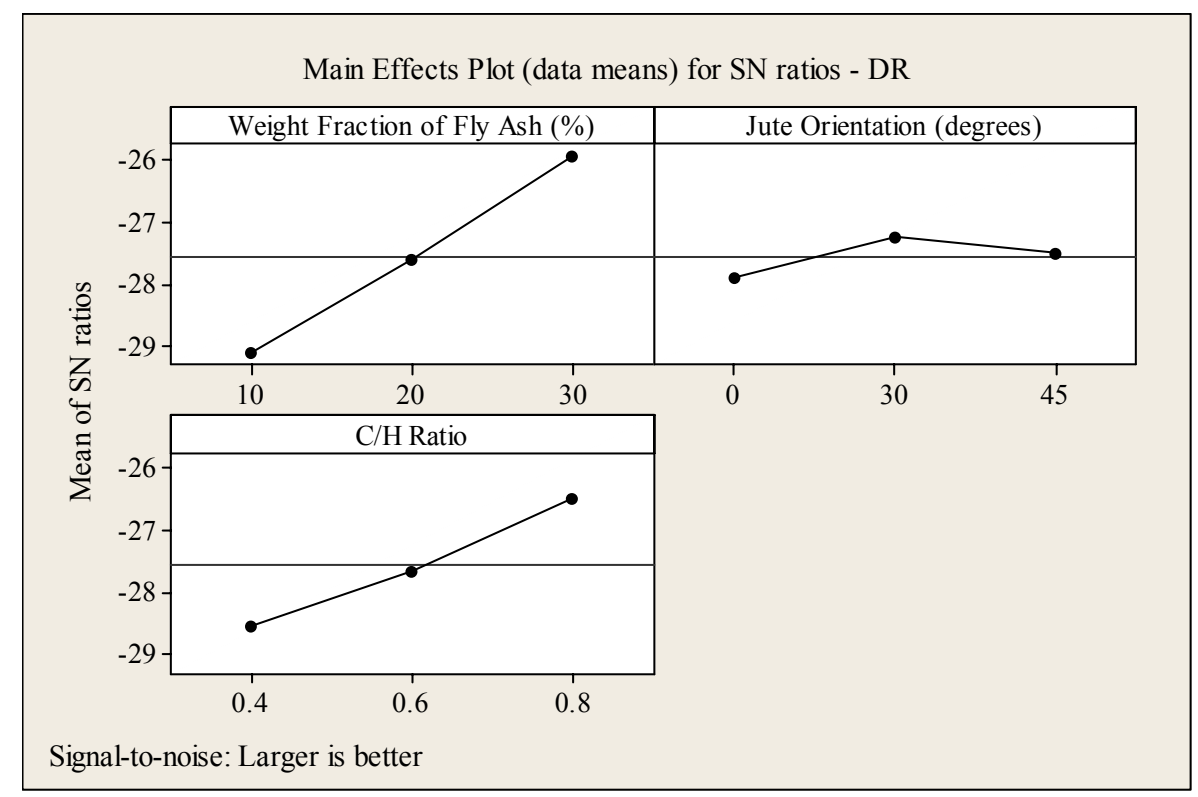

Signal-to-noise: Larger is better

Figure 9. Effect of control factors on damping ratio

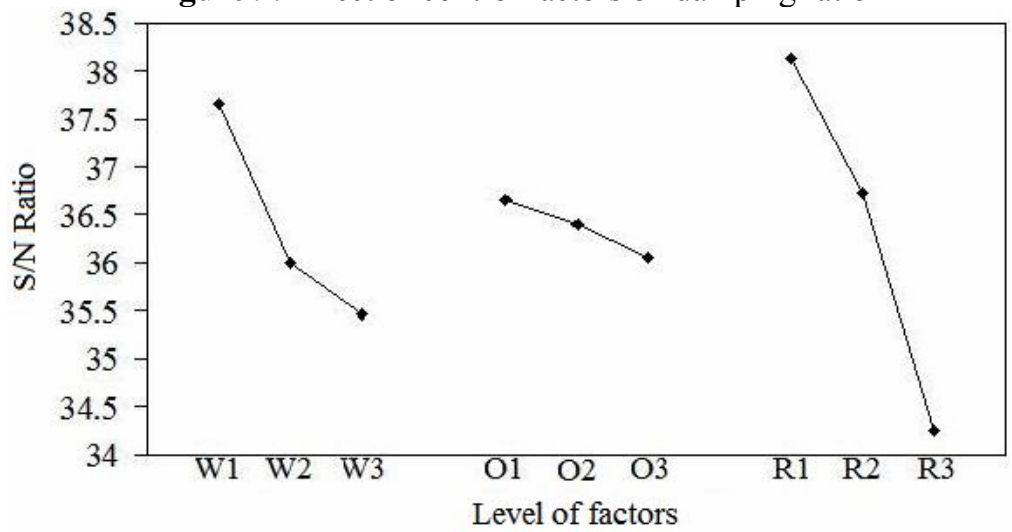

Figure 10. Plot of factor effects on $\mathrm{S} / \mathrm{N}$ ratio of natural frequency 


\subsubsection{Analysis of variance (ANOVA)}

The use of ANOVA is to analyze the influence of material and geometrical parameters on DR and NF. This analysis is carried out for a level of significance of 5\%, i:e., the level of confidence 95\% (Ross, 1988; Roy, 1990) Table 7 shows the results of ANOVA analysis for DR while results of NF are presented in Table 8. The last column (P) in these tables indicates the probability of significance of major control factors. Smaller the value, higher would be the percentage contribution of the factor on the total variation indicating higher degree of influence on the results.

Table 7. ANOVA results for damping ratio

\begin{tabular}{lccccc}
\hline Source of variances & Dof & Seq SS & Adj MS & F & P \\
\hline Fly ash weight fraction, W (\%) & 2 & 15.1350 & 7.56751 & 703.66 & 0.001 \\
Orientation of Jute Fabric, O $\left({ }^{\circ}\right)$ & 2 & 0.6272 & 0.31359 & 29.16 & 0.033 \\
C/H Ratio, R & 2 & 6.5276 & 3.26381 & 303.48 & 0.003 \\
\hline Residual Error & 2 & 0.0215 & 0.01075 & ---- & ---- \\
Total & 8 & 22.3113 & ----- & ---- & ---- \\
\hline
\end{tabular}

Notes: Dof $=$ Degree of freedom. Seq $=$ Sequential. Adj = Adjusted. SS = Sum of squares

One can observe from the ANOVA table 7 that, the fly ash weight fraction $(\mathrm{P}=0.001), \mathrm{C} / \mathrm{H}$ ratio $(\mathrm{P}=0.003)$ and jute skin orientation ( $\mathrm{P}=0.033)$ are significant in declining order of significance on DR. Among the control factors, fly ash weight fraction $(\mathrm{P}=0.001)$ show significance of contribution on DR. From the above analysis, we conclude that jute skin orientation $(\mathrm{P}=0.033)$ is having comparatively less significant contribution on DR, which indicates that there is no appreciable increase (rather it decreases) in DR by increasing jute skin orientation from $30^{\circ} / 60^{0}$ to $45^{0} / 45^{0}$. This decreasing trend might be because of the fact that nullifying effect creeping in at $45^{0} / 45^{0}$ of associated parameters.

Table 8. ANOVA results for natural frequency

\begin{tabular}{lccccc}
\hline Source of variances & Dof & Seq SS & Adj MS & F & P \\
\hline Fly ash weight fraction, W (\%) & 2 & 7.8987 & 3.9493 & 41.52 & 0.024 \\
Orientation of Jute Fabric, $\mathrm{O}\left({ }^{\circ}\right)$ & 2 & 0.5537 & 0.2769 & 2.91 & 0.256 \\
C/H Ratio, R & 2 & 23.1940 & 11.5970 & 121.92 & 0.008 \\
\hline Residual Error & 2 & 0.1902 & 0.0951 & ---- & ----- \\
Total & 8 & 31.8366 & ----- & ---- & ---- \\
\hline
\end{tabular}

From Table 8 , it is clear that $\mathrm{C} / \mathrm{H}$ ratio $(\mathrm{P}=0.008)$ is having great influence on NF. Remaining factors i.e. fly ash weight fraction $(\mathrm{P}=0.024)$ and jute skin orientation $(\mathrm{P}=0.256)$ is having relatively less significant contribution. Even though jute skin orientation is the least contributing factor in both cases ( $\mathrm{P}=0.033$ for $\mathrm{DR}$ and $\mathrm{P}=0.256$ for NF), it can not be neglected in order to develop a multiple regression model as it is one of the major load bearing element in sandwich structures.

\subsubsection{Surface plots}

For both the properties under study, it is clear that weight fraction of fly ash and $\mathrm{C} / \mathrm{H}$ ratio is having more contribution compared to jute orientation (table 7 and table 8). Detailed diagrams in the form of surface plots are presented for the properties under study as a function of fly ash weight fraction and $\mathrm{C} / \mathrm{H}$ ratio in figures 11 and 12.

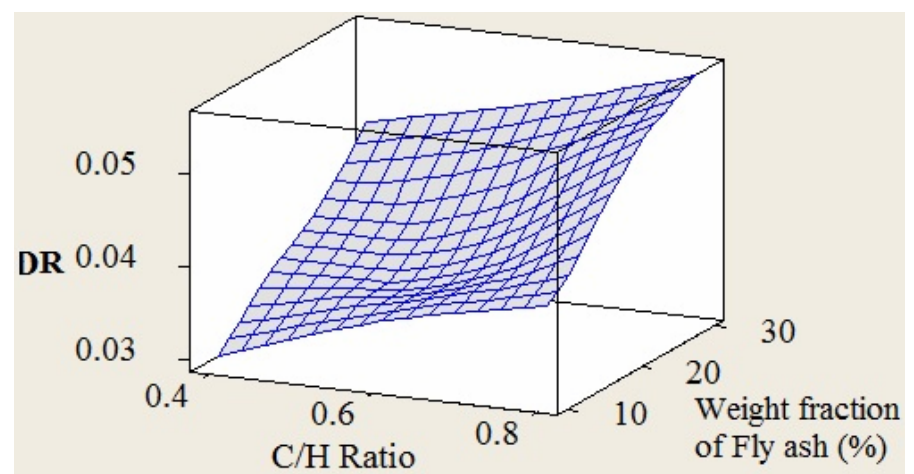

Figure 11. Surface plot of damping ratio

Figure 11 depicts lower amounts of filler addition resulting in not an appreciable rise in damping ratio. Same inference can be drawn even at higher $\mathrm{C} / \mathrm{H}$ ratio. Higher value of $\mathrm{DR}$ is observed at higher amounts of control factors. DR increases with increase in fly ash weight fraction and $\mathrm{C} / \mathrm{H}$ ratio. This might be because of the fact that, with increase in both control factors energy absorption increases due to filler addition and increased thickness. 


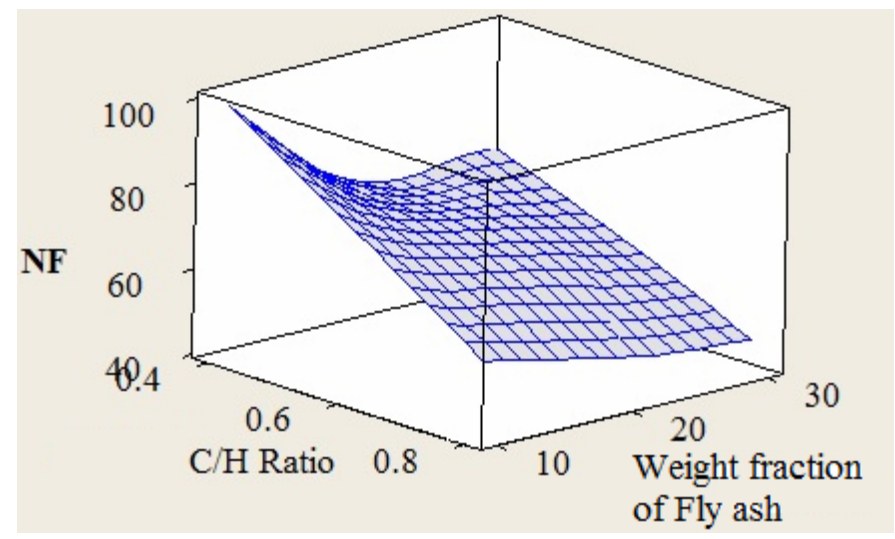

Figure 12. Surface plot of natural frequency

Natural frequency decreases with increase in controllable factors (Figure 12). Decreasing trend is observed to be more prominent and governing in case of $\mathrm{C} / \mathrm{H}$ ratio than weight fraction of fly ash. Lowest natural frequency is reported at $30 \%$ filler addition and $0.8 \mathrm{C} / \mathrm{H}$ ratio. This is attributed towards toughening or stiffening effect due to fly ash reinforcement in thicker cores.

\subsubsection{Multiple linear regression models}

To establish the correlation between the material, geometrical parameters like weight fraction of fly ash, orientation of jute skin, $\mathrm{C} / \mathrm{H}$ ratio and $\mathrm{DR}$, NF multiple linear regression model is obtained (Montgomery, 2001) using statistical software "MINITAB R14". All the terms are included in the model.

The regression equation for DR is obtained as follows,

$D R=0.0116+0.000769 W+0.000028 O+0.0250 R$

The regression equation for NF is obtained as follows,

$N F=134-0.9 W-0.16 O-74.3 R$

where $W=$ Fly ash weight fraction $(\%), O=$ Jute skin orientation $\left({ }^{\circ}\right), R=\mathrm{C} / \mathrm{H}$ ratio

By substituting the recorded values of the variables for Eq. (7) and (8), DR and NF of the sandwich composite can be calculated. The positive value of the coefficients suggests that the DR and NF of material increases with their associated variables. Whereas the negative value of the coefficients suggest decrease in properties with the increase in associated variables. The important factor affecting the DR is the weight fraction of fly ash (table 7) and the coefficient associated with it is positive. This suggests that the DR increases with increasing the weight fraction of fly ash for the tested range. The coefficients for the remaining factors are also observed to be positive indicating increase in $\mathrm{DR}$ with increasing $\mathrm{C} / \mathrm{H}$ ratio and jute skin orientation. Main effects plot counteracts the fact of positive coefficient for orientation. This might be due to marginal decrease in DR from $30^{\circ} / 60^{\circ}$ to $45^{\circ} / 45^{\circ}$ which coefficient might unable to capture. The increase in DR with increase in $W$ and $R$ is attributed towards increasing stiffness as ash content increases. For $30^{\circ} / 60^{\circ}$ jute orientation higher damping ratio is observed. This may be because of higher relative movement between the fibers (sort of rolling effect) at $30^{\circ}$ compared to stretching effect at $0^{\circ} / 90^{\circ}$ and nullifying effect at $45^{\circ} / 45^{\circ}$.

$\mathrm{C} / \mathrm{H}$ ratio is having great influence on $\mathrm{NF}$ (table 8). Coefficients for all the control parameters are observed to be negative, suggesting decrease in NF with increase in $W, O$ and $R$. This is attributed towards lower proportionate increase in stiffness compared to the total mass of sandwiches.

\subsubsection{Confirmation test}

The confirmation tests are performed by selecting the set of parameters as shown in Table 9. For these selected parameters experiments are conducted with five replicates each. Table 10 presents the comparison of DR and NF results from the mathematical model developed in the present work (Eq. (7) and (8)), with the values obtained experimentally.

Table 9. Parameters used in the confirmation DR and NF test

\begin{tabular}{cccc}
\hline Test & Fly ash weight fraction, $\mathrm{W}(\%)$ & Orientation of Jute Fabric, $\mathrm{O}\left({ }^{\circ}\right)$ & $\mathrm{C} / \mathrm{H}$ Ratio, $\mathrm{R}$ \\
\hline 1 & 5 & $0^{0}$ & 0.3 \\
2 & 15 & $30^{0}$ & 0.5 \\
3 & 25 & $45^{0}$ & 0.7 \\
\hline
\end{tabular}


Table 10. Confirmation tests and their comparison with regression model

\begin{tabular}{c|ccc|ccc}
\hline \multirow{2}{*}{ Test } & \multicolumn{3}{|c|}{ Damping Ratio } & \multicolumn{3}{c}{ Natural Frequency } \\
\cline { 2 - 7 } & Expt. & $\begin{array}{c}\text { Reg. model } \\
\text { (Equation (7)) }\end{array}$ & $\begin{array}{c}\text { Error } \\
(\%)\end{array}$ & Expt. & $\begin{array}{c}\text { Reg. model } \\
\text { (Equation (8)) }\end{array}$ & Error (\%) \\
\hline 1 & 0.02499 & 0.022945 & 8.18 & 116.23 & 107.21 & 7.76 \\
2 & 0.03842 & 0.036475 & 5.06 & 88.26 & 78.55 & 11.00 \\
3 & 0.05321 & 0.049585 & 6.81 & 56.89 & 52.29 & 8.09 \\
\hline
\end{tabular}

From the analysis of the referred table, we can observe that the calculated error varies from $5 \%$ to $9 \%$ for DR and varies from $7 \%$ to $11 \%$ for NF. This indicates that the multiple regression equation derived above correlate the evaluation of the DR and NF in the FG sandwiches with the reasonable degree of approximation.

\section{Conclusion}

An experimental study is carried out for particulate filled functionally graded rubber sandwiches to investigate the effect of fly ash weight fraction, jute skin orientation and $\mathrm{C} / \mathrm{H}$ ratio on DR and NF analysis. Taguchi's robust design method can be used to analyze damping ratio and natural frequency of the sandwiches with FG cores as described in the paper. The following generalized conclusions can be drawn from the work.

(1) Presence of gradation in core is confirmed and quantified through weight method.

(2) DR and NF characteristics of FG sandwich composites can be successfully analyzed using Taguchi experimental design scheme. Taguchi method provides a simple, systematic and efficient methodology for identifying significant control factors.

(3) An optimal parameter combination happens to be fly ash weight fraction of $30 \%$, jute skin orientation of $30^{0} / 60^{\circ}$ and $\mathrm{C} / \mathrm{H}$ ratio of 0.8 for DR which leads to higher parameter value. Control factor combination of $10 \%$ fly ash weight fraction, $0^{0} / 90^{0}$ jute skin orientation and 0.4 of $\mathrm{C} / \mathrm{H}$ ratio registered higher response for NF. DR of sandwich increases with weight fraction of fly ash and $\mathrm{C} / \mathrm{H}$ ratio. $\mathrm{NF}$ of sandwich sample decreases with increase in weight fraction of fly ash, $\mathrm{C} / \mathrm{H}$ ratio and jute skin orientation.

(4) The results indicate that fly ash weight fraction and $\mathrm{C} / \mathrm{H}$ ratio are the most significant factors affecting DR and NF. Although the effect of jute skin orientation is significantly less for both the properties compared to other factors, it cannot be ignored as it is the major load bearing component in the sandwich structures.

(5) The residual errors associated with the ANOVA are observed to be lower for the factors and the coefficient of regression obtained with the multiple regression values show that the satisfactory correlation is obtained.

(6) The confirmation tests showed that error associated with damping ratio of the composite varies from $6 \%$ to $12 \%$ while that for natural frequency it happens to be in the range of $4 \%$ to $11 \%$.

(7) In future, the study can be extended to gradation on the basis of wall thickness of hollow spheres and different work materials.

(8) Damping ratio is the most important parameter in energy absorption related applications. We think that the present sandwich system can be used as dampers for the vehicles on the front side. Furthermore, the sandwich system with W3 O2 R3 configuration (maximum DR) can be utilized for ballistic applications by having a stack of about 10 to 12 such sandwiches which can effectively arrest a bullet. This could be the best proposition as a replacement for heavy sand bags used for guarding military posts.

\section{Acknowledgement}

Authors wish to thank Dr. K. V. Gangadharan, Professor, Department of mechanical engineering, National Institute of Technology Karnataka, Surathkal for the support extended for carrying out the experiments in Dynamics Laboratory.

\section{References}

Ahmed K.H., 1971. Free vibration of curved sandwich beams by the method of finite elements. Journal of Sound and vibration, Vol. 18, pp. 61-74.

Ahmed K.M., 1972. Dynamic analysis of sandwich beams, Journal of Sound and Vibration, Vol. 21, pp. 263-276.

Allen H., 1969. Analysis and design of structural sandwich panels, Oxford, Pergamon Press.

Amada S., Ichikawa Y., Munekata T., Nagase V., Shimizu H., 1997. Fiber texture and mechanical graded structure of bamboo, Composites Part B, Vol. 28, pp. 13-20.

Amada S., Untao S., 2001. Fracture properties of bamboo, Composites Part B, Vol. 32, 451-459.

Ambartsumyan S.A., 1970. Theory of Anisotropic Plates (English translation), Technomic, Stanford.

Apetre N.A., Sankar B.V., Ambur D.R., 2003. Functionally sandwich core with arbitrary variation in properties, Proceedings of the $44^{\text {th }}$ AIAA/ASME/ASCE/AHS/ASC structures, structural dynamics and materials conference, Washington. 
Arikoglu A., Ozkol I., 2010. Vibration analysis of composite sandwich beams with viscoelastic core by using differential transform method, Composite Structures, pp. 3031-3039.

Arvin H., Sadighi M., Ohadi A. R., 2010. A numerical study of free and forced vibration of composite sandwich beam with viscoelastic core, Composite Structures, Vol. 92, pp. 996-1008.

ASTM standard test method for density of sandwich core materials, C 271-05.

ASTM standard test method for measuring vibration damping properties of materials, E756-05(2010).

Avery J.L., Sankar B.V., 2000. Compressive failure of sandwich beams with debonded facesheets, Journal of Composite Materials, Vol. 34, pp. 1176-1199.

Baber T.T., Maddox R.A., Orozco C.E., 1998. A finite element model for harmonically excited viscoelastic sandwich beams, Computers \&Structures, Vol. 66, pp. 105-113.

Banerjee J. R., 2003. Free vibration of sandwich beams using the dynamic stiffness method, Computers and structures, Vol. 81, pp. 1915-1922.

Basavarajappa S., Chandramohan G., 2005. Wear studies on metal matrix composites: a Taguchi approach, J. Mater. Sci. Technol, Vol. 21, pp. 845-850.

Berger H.M., 1955. A new approach to the analysis of large deflection of plates, ASME, J. Appt. Mech., Vol. 22, pp. 465-472.

Berthelot J.M., 1999. Composite Materials: Mechanical Behavior and Structural Analysis, New York, Springer Edition.

Birman V., 2002. On the choice of shear correction factor in sandwich structures, Journal of Sandwich Structures and Materials, Vol. 4, pp. 83-95.

Bozhevolnaya E., Sun J.Q., 2004. Free vibration analysis of curved sandwich beams, Journal of Sandwich Structures and Materials, Vol. 6, pp. 47-73.

Cannillo V., Lusvarghi L., Siligardi C., Sola A., 2007. Prediction of the elastic properties profile in glass-alumina functionally graded materials, J of the European Ceramic Society, Vol. 27, pp. 2393-400.

Chakraborty A., Gopalakrishnan S., Reddy J.N., 2003. A new beam finite element for the analysis of functionally graded materials, Intenational Journal of Mechanical sciences, Vol. 45, pp. 519-39.

Chandra R., 1976. Large deflection vibration of cross-ply laminated plates with certain edge conditions, J. Sound Vibr., Vol. 47, pp. 509-514.

Chandra R., Raju B.B., 1975. Large amplitude flexural vibrations of cross-ply laminated composite plates, Fibre Sri. Tech., Vol. 8, pp. 243-264.

Chehel Amirani M., Khalili S.M.R., Nemati N., 2009. Free vibration analysis of sandwich beam with FG core using the element free Galerkin method, Composite Structures,Vol. 90, pp. 373-379.

Chia, C.Y., 1980. Non-linear Analvsis of Plates, McGraw- Hill, New York.

Choi N.S., 2003. A double cantilever sandwich beam method for evaluating dynamic characteristics of rubber materials, JSME International Journal series C-Mechanical Systems Machine Elements \& Manufacturing, Vol. 46, pp. 666-674.

Dias C.M.R., Savastano Jr. H., John V.M., 2010. Exploring the potential of functionally graded materials concept for the development of fiber cement, Construction and Building Materials, Vol. 24, pp. 140-146.

Elangovan K., Sathiya Narayanan C., 2010. Application of Taguchi approach on investigation of formability for perforated Al 8011 sheets, International Journal of Engineering, Science and Technology, Vol. 2, pp. 300-309.

El-Hadek M., Tippur H.V., 2003. Dynamic fracture parameters and constraint effects in functionally graded syntactic epoxy foams, International Journal of Solids Structures, Vol. 40, pp. 1885-1906.

Evans A.G., Hutchinson J.W., Fleck N.A., Ashby M.F., Wadley H.N.G., 2001. The topological design of multifunctional cellular metals, Progress in Material Science, Vol. 46, pp. 309-327.

Fasana A., Marchesiello S., 2001. Rayleigh-Ritz analysis of sandwich beams, Journal of Sound and Vibration, Vol. 241, pp. 643652.

Ferreira J.A.M., Costa J.D.M., 1998. Static behavior of PVC foam composite sandwich panel, J. Cellular Polymers, Vol. 17, pp. 177-192.

Ferrigno T.H., 1978. Handbook of Fillers and Reinforcements for Plastics, Ed. Katz H.S., Milewski J.V. New York, Van Nostrand Reinhold Co., pp. 66-71.

Fukui Y., 1991. Fundamental investigation of functionally graded materials manufacturing system using centrifugal force, JSME International Journal Series III, Vol. 34, pp. 144-148.

Fukui Y., Yamanaka N., Enokida Y., 1997. Bending strength of an AI-AI3Ni functionally graded material, Composites Part B, Vol. 28, pp. 37-43.

Ganesan N., Pradeep V., 2005. Buckling and vibration of sandwich beams with viscoelastic core under thermal environments, Journal of Sound and Vibration, Vol. 286, pp. 1067-1074.

Gowda T.M., Naidu A.C.B., Rajput Chhaya, 1999. Some mechanical properties of untreated jute fabric reinforced polyester composites, Composites Part A: Applied Science and Manufacturing, Vol. 30, pp. 277-284.

Hao M., Rao M.D., 2005. Vibration and damping analysis of a sandwich beam containing a viscoelastic constraining layer, Journal of Composite Materials, Vol. 39, pp. 1621-1643.

Hashemi S.M., Adique E.J., 2009. Free Vibration analysis of Sandwich Beams: A Dynamic Finite Element, International Journal of Vehicle Structures \& Systems (IJVSS), Vol. 1, pp. 59-65. 
Hassert J.E., Nowinski J.L., 1962. Non-linear transverse vibration of flat rectangular orthotropic plate supported by stiff ribs, Proc. 5th Int. Symp. Space Tech. Sri., Tokyo, pp. 561-570.

Hwu C., Chang W. C. and Gai H. S., 2004. Vibration suppression of sandwich beams, Journal of sound and vibration, Vol. 272, pp. 1-20.

Kapuria S., Dumir P.C., Jain N.K., 2004. Assessment of zigzag theory for static loading, buckling, free and forced response of composite and sandwich beams, Composite Structures, Vol. 64, pp. 317-327.

Kashtalyan M., Menshykova M., 2009. Three-dimensional elasticity solution for sandwich panels with a functionally graded core, Composite Structures, Vol. 87, pp. 36-43.

Kishore, Kulkarni S.M., Sharathchandra S., Sunil D., 2002. On the use of an instrumented setup to characterize the impact behavior of an epoxy system containing varying fly ash content, Polymer testing, Vol. 21, pp. 763-771.

Koizumi M., 1997. FGM Activites in Japan, Compos. Part B: Eng., Vol. 28, pp. 1-4.

Kulkarni S.M, Anuradha D., Murthy C.R.L., Kishore, 2002. Analysis of filler-fibre interaction in fly ash filled short fibre-epoxy composites using ultrasonic NDE, Bulletin of Materials Science, Vol. 25: pp. 137-40.

Kulkarni S.M, Kishore, 2002. Effects of surface treatments and size of fly ash particles on the compressive properties of epoxy based particulate composites, J of Materials Science, Vol. 37, pp. 4321-26.

Lambros J., Santare M.H., Li H., Sapna G.H., 1999. A novel technique for the fabrication of laboratory scale model of FGM, Experimental Mechanics, Vol. 39, pp. 184-190

Le-Chung Shiau, Shih-Yao Kuo, 2006. Free Vibration of Thermally Buckled Composite Sandwich Plates, Journal of Vibration and Acoustics, ASME, Vol. 128, pp. 1-7.

Li Q., Iu V.P., Kou K.P., 2008. Three-dimensional vibration analysis of functionally graded material sandwich plates, Journal of Sound and Vibration, Vol. 311, pp. 498-515.

Mahapatra S.S., Chaturvedi V., 2009. Modelling and analysis of abrasive wear performance of composites using Taguchi approach, International Journal of Engineering, Science and Technology, Vol. 1,pp. 123-135.

Marc André Meyers, Po-Yu Chen, Albert Yu-Min Lin, Yasuaki Seki, 2008. Biological materials: Structure and mechanical properties, Progress in Materials Science, Vol. 53, pp.1-206.

Mathivanan D., Nouby M., Vidhya R., 2010. Minimization of sink mark defects in injection molding process - Taguchi approach, International Journal of Engineering, Science and Technology, Vol. 2, pp. 13-22.

Mead D.J., Markus S., 1968. The forced vibration of a three-layer, damped sandwich beam with arbitrary boundary conditions, Journal of Sound and Vibration, Vol. 10, pp. 163-175.

Mead D.J., Sivakumaran S., 1966. The Stodola method applied to sandwich beam vibration, Proceedings of the Symposium on Numerical Methods for Vibration Problems, University of Southampton, UK.

Meyer-Piening H.R., 2004. Application of the elasticity solution to linear sandwich beam plate and shell analyses, Journal of Sandwich Structures and Materials, Vol. 6, pp. 295-312.

Mohan R., Kishore, Shridhar M.K., Rao R.M.V.G.K., 1983. Compressive strength of jute-glass hybrid fibre composites, J of Mat Sci Letters, Vol. 2, pp. 99-102.

Mohan, Rengarajan, Kishore, 1985. Jute-Glass sandwich composites, J of Reinforced plastics and composites, Vol. 4, pp. 186-194.

Mohapatra R., Rajagopala Rao J., 2001. Some aspects of characterisation, utilisation and environmental effects of fly ash, $J$ of Chem tech and Biotech, Vol. 76, pp. 9-26.

Montgomery D.C., 2001. Design and Analysis of experiments, Wiley, New York.

Nabarrete A., de Almeida S.F.M., Hansen J.S., 2003. Sandwich-plate vibration analysis: three-layer quasi-three-dimensional finite element model, AIAA Journal, Vol. 41, pp. 1547-1555.

Naghipour M., Taheri F., Zou G. P., 2005. Evaluation of vibration damping of glass-reinforced-polymer-reinforced glulam composite beams, Journal of Structural Engg., ASCE, Vol. 131, pp. 1044-1050.

Noureddine E.M., Abdelouahed T., Noureddine Z., Ismail M. and El Abbes Adda Bedia, 2011. A new hyperbolic shear deformation theory for buckling and vibration of functionally graded sandwich plate, Int J of Mechanical Sciences, Vol. 53, pp. 237-247.

Numayr K.S., Qablan H.A., 2005. Effect of torsion and warping on the free vibration of sandwich beams, Mechanics of Composite Materials, Vol. 41, pp. 109-118.

Ostergaard R.C., 2006. Proceedings of the $27^{\text {th }}$ Riso International Symposium on Materials Science, Denmark.

Pedlow J.W., 1978. Cenospheres, in Coal ash utilization Fly ash, Bottom ash and Slag, Ed. Torrey S. New Jersy, Noyes Data Corporation, pp. 353-362.

Phadke M.S., 1989. Quality Engineering Using Robust Design, Englewood Cliffs, NJ Prentice-Hall.

Plagianakos T.S., Saravanos D.A., 2004. High-order layerwise mechanics and finite element for the damped dynamic characteristics of sandwich composite beams, International Journal of Solids and Structures, Vol. 41, pp. 6853-6871.

Plantema F., 1966. Sandwich construction, Wiley, New York.

Rahmani O., Khalili S.M.R., Malekzadeh K., 2010. Free vibration response of composite sandwich cylindrical shell with flexible core, Composite Structures, Vol. 92, pp. 1269-1281

Rahmani O., Khalili S.M.R., Malekzadeh K., Hadavinia H., 2009. Free vibration analysis of sandwich structures with a flexible functionally graded syntactic core, Composite Structures, Vol. 91, pp. 229-235. 
Rao D.K., 1978. Frequency and loss factors of sandwich beams under various boundary conditions, Journal of Mechanical Engg. Sciences, Vol. 20, pp. 271-82.

Reddy J.N, Wang C.M. and Kitipornchi S., 1999. Axisymmetric Bending of functionally graded circular and annular plates,. Euro. J. Mech. And solids, Vol. 18, pp. 185-199.

Reddy J.N., Chao W.C., 1981. Large deflection and large amplitude free vibrations of laminated composite material plates, Comput. Sfruct., Vol. 13, pp. 341-347.

Reddy J.N., Chao W.C., 1982. Non-linear oscillations of laminated anisotropic rectangular plates, ASME, J. Appl. Mech., Vol. 49, pp. 396-402.

Reddy J.N., Cheng Z.Q., 2001. Three-dimensional trenchant deformations of functionally graded rectangular plates, Euro. J. Mech. And solids, Vol. 20, pp. 841-855.

Ross P.J., 1996. Taguchi Techniques for Quality Engineering: Loss Function, Orthogonal Experiments, Parameter and Tolerance Design, $2^{\text {nd }}$ ed., New York, McGraw-Hill.

Ross Phillip J., 1988. Taguchi technique for quality engineering, McGraw-Hill, New York.

Roy K.R., 1990. A primer on Taguchi Method, Van Nostrad Reinhold, New York.

Ruzzene M., 2004. Vibration and sound radiation of sandwich beams with honeycomb truss core, Journal of Sound and Vibration, Vol. 227, pp. 741-763.

Sanjit Moshat, Saurav Datta, Asish Bandyopadhyay, Pradip Kumar Pal, 2010. Optimization of CNC end milling process parameters using PCA-based Taguchi method, International Journal of Engineering, Science and Technology, Vol. 2, pp. 92102.

Sanjit Moshat, Saurav Datta, Asish Bandyopadhyay, Pradip Kumar Pal, 2010. Parametric optimization of CNC end milling using entropy measurement technique combined with grey-Taguchi method, International Journal of Engineering, Science and Technology, Vol. 2, pp. 1-12.

Sankar B.V., 2001. An elasticity solution for functionally graded beams, Comp Sci \& tech, Vol. 61, pp. 689-699.

Sarkar P., Datta S., Nicholson P.S., 1997. Functionally graded ceramic/ceramic and metal/ceramic composites by electrophoretic deposition, Composites Part B, Vol. 28, pp. 49-56.

Sathyamoorthy M., 1983. Non-linear vibrations of plates: a review, Shock Vibr. Digest 15, pp. 3-16.

Saurav Datta, Siba Sankar Mahapatra, 2010. Modeling, simulation and parametric optimization of wire EDM process using response surface methodology coupled with grey-Taguchi technique, International Journal of Engineering, Science and Technology, Vol. 2, pp. 162-183.

Sh. Hosseini-Hashemi, M. Fadaee and S.R. Atashipour, 2011. A new exact analytical approach for free vibration of ReissnerMindlin functionally graded rectangular plates, Intl J of Mechanical Sciences, Vol. 53, pp. 11-22.

Shah A.N, Lakkad S.C., 1981. Mechanical properties of jute-reinforced plastics, Fibre Science and Technology, Vol. 15, pp. 4146.

Siddhartha A., Amar Patnaik, Amba Bhatt, 2011. Mechanical and dry sliding wear characterization of epoxy- $\mathrm{TiO}_{2}$ particulate filled functionally graded composites materials using Taguchi design of experiment, Materials and Design, Vol. 32, pp. 615-27.

Sisemore C.L., Darvennes C.M., 2002. Transverse vibration of elastic-viscoelastic-elastic sandwich beams: compressionexperimental and analytical study, Journal of Sound and Vibration, Vol. 252, pp. 155-167.

Sokolinsky V.S., Nutt S.R., Frostig Y., 2002. Boundary condition effects in free vibrations of higher-order soft sandwich beams, AIAA Journal, Vol. 40, pp. 1220-1227.

Sokolinsky V.S., Von Bremen H.F., Lavoie J.A., Nutt S.R., 2004. Analytical and experimental study of free vibration response of softcore sandwich beams, Journal of Sandwich Structures and Materials, Vol. 6, pp. 239-261.

Suresh S., 2001. Graded materials for resistance to contact deformation and damage, Science, Vol. 292, pp. 2447-2451.

Suresh S., Mortensen A., 1998. Fundamentals of Functionally Graded Materials, IOM Communications Limited, London, United Kingdom.

Taguchi G., 1993. Taguchi on robust technology development methods, ASME Press, New York, pp. 1-40.

Taguchi G., Konishi S.,1987. Taguchi methods, orthogonal arrays and linear graphs, tools for quality engineering, American Supplier Institute, Dearborn, MI, pp. 35-38.

Venkateswarlu G., Davidson M.J., Tagore G.R.N., 2010. Influence of process parameters on the cup drawing of aluminium 7075 sheet, International Journal of Engineering, Science and Technology, Vol. 2, pp. 41-49.

Vinson J., 1999. The Behavior of Sandwich Structures of Isotropic and Composite Materials, Pennsylvania, Technomic Publishing Company Inc.

Wadley H.N.G., Fleck N.A., Evans A.G., 2003. Fabrication and structural performance of periodic cellular metal sandwich structures, Composite Science and Technology, Vol. 63, pp. 2331-2343.

Watari F., Yokoyama A., Saso F., Uo M., Kawasaki T., 1997. Fabrication and properties of functionally graded dental implant, Composites Part B, Vol. 28, pp. 5-11.

Whitney J.M., Leissa A.W., 1969. Analysis of heterogeneous anisotropic plates, ASME, J. Appl. Mech., Vol. 36, pp. 261-266.

Wu C.I., Vinson J.R., 1969. On non-linear oscillations of plates composed of composite materials, J. Compos. Mater., Vol. 3, pp. 548-561.

Wu C.I., Vinson J.R., 1971. Non-linear oscillations of laminated specially orthotropic plates with clamped and simply supported edges, I. Acoust. Sot. Am., Vol. 49, pp. 1561-1567. 
Yamanouchi M., Koizumi M., Shiota I., 1990. Proc. the First Int. Symp.Funct. Grad. Mater., Sendai, Japan.

Yang M., Qiao P., 2005. Higher-order impact modeling of sandwich structures with flexible core, International Journal of Solids and Structures, Vol. 42, pp. 5460-5490.

Yang W.P., Chen L.W., Wang C.C., 2005. Vibration and dynamic stability of a traveling sandwich beam, Journal of Sound and Vibration, Vol. 285, pp. 597-614.

Zenkert D., 1995. An introduction to sandwich construction, SheWeld, UK, Engineering Materials Advisory Service.

Zenkert D., 1997. Handbook of Sandwich Construction, EMAS Publishing, Chameleon Press Limited, London.

\section{Biographical notes}

M. R. Doddamani received M. Tech. from Gogte Institute of Technology, Belgaum, India in 2003. He is a Assistant Professor in the Department of Mechanical Engineering, Gogte Institute of Technology, Belgaum, India. Presently he is persuing his research under the guidance of Dr. S. M. Kulkarni at National Institute of Technology Karnataka Surathkal India. He has more than 8 years of experience in teaching and research. His current areas of research interest are functionally graded Materials. He has presented more than ten research articles in international conferences. He has filed a patent to Govt. of India last year.

Dr. S. M. Kulkarni is currently a Professor in the Department of Mechanical Engineering, National Institute of Technology Karnataka Surathkal India. He has obtained his Ph. D from Indian Institute of Science (IISc), Bangalore. He is also recipient of best thesis award in the Mechanical Engineering Division at IISc. He has more than 20 years of experience in teaching and research. His current areas of research are Composite Materials, Application of CAD for composites, Rapid processing of composites and Smart composites. He has published more than twenty five papers in referred International journals. He has also presented more than thirty research articles in national and international conferences. He is currently dealing with few projects on composite sponsored by DST, Government of India.

Received February 2011

Accepted April 2011

Final acceptance in revised form May 2011 